\title{
Validation of the Filipino-Translated Version of the Michigan Neuropathy Screening Instrument among Filipino Patients with Diabetes Mellitus Seen at the Philippine General Hospital*
}

\author{
Daryl Jade Dagang, ${ }^{1}$ Jose Danilo Diestro, ${ }^{2}$ Geohana Hamoy-Jimenez, ${ }^{2}$ \\ Iris Thiele Isip-Tan, ${ }^{1}$ Jose Paciano Baltazar Reyes ${ }^{2}$ \\ ${ }^{1}$ Section of Endocrinology, Diabetes and Metabolism, Department of Medicine, Philippine General Hospital \\ ${ }^{2}$ Section of Neurology, Department of Neurosciences, Philippine General Hospital
}

\begin{abstract}
Objectives. To assess the validity of the Filipino-translated version of the Michigan Neuropathy Screening Instrument (MNSI) in screening for diabetic neuropathy among Filipino patients with diabetes mellitus using nerve conduction velocity (NCV) as gold standard and to determine the most accurate cut-off score for the diagnosis of neuropathy using MNSI.

Methodology. A cross-sectional analytic study was done among adult diabetic patients. The original MNSI Questionnaire was translated and back-translated to the Filipino language. Each patient answered the Filipino version of MNSI Questionnaire followed by a lower extremity examination done by the investigator. All patients underwent NCV as reference standard. Sensitivity and specificity of MNSI were determined.

Results. We studied a total of 150 subjects. Eighty-seven (58\%) were diagnosed to have diabetic neuropathy based on NCV. The sensitivity and specificity of the MNSI Questionnaire improved to $73.6 \%$ and $52.4 \%$ respectively when the cut off was reduced to $\geq 4$, whereas for the MNSI Examination, the sensitivity and specificity improved to $86.2 \%$ and $55.6 \%$ respectively when the cut off was reduced to $\geq 1$. Combining both MNSI Questionnaire and MNSI Examination further improves the sensitivity to $95.4 \%$ whereas specificity is at $39.7 \%$.
\end{abstract}

Conclusion. The analyses in 150 subjects confirm that the Filipino-version of MNSI is a valid screening tool for diabetic neuropathy when compared with NCV as gold standard.

Key words: diabetic neuropathy, questionnaire, Filipino, diabetes mellitus

\section{INTRODUCTION}

Diabetic neuropathy is one of the most common complications of both Type 1 and Type 2 diabetes mellitus. In a population-based study done in Rochester, Minnesota, as many as $66 \%$ of patients with Type 1 diabetes mellitus and 59\% in Type 2 diabetes mellitus has some form of neuropathy. ${ }^{1}$ At the time of diagnosis of Type 2 diabetes a prevalence of $12.3 \%$ was reported in the United Kingdom Prospective Diabetes Study (UKPDS), and in the 15-year follow-up, prevalence of neuropathy increased to $36.8 \%$ despite treatment. ${ }^{2}$

Early diagnosis of diabetic neuropathy can decrease patient morbidity by allowing for potential therapeutic interventions, including patient education and regular foot surveillance. Traditionally, the diagnosis of diabetic neuropathy was based on subjective interpretation of clinical symptoms and specific signs such as reduced ankle

\section{eISSN 2308-118x}

Printed in the Philippines

Copyright (C) 2016 by the JAFES

Received: May 17, 2016. Accepted: July 11, 2016.

https://doi.org/10.15605/jafes.031.02.06 reflexes and loss of vibratory sensation. ${ }^{3}$ There has been no single diagnostic test for the detection of diabetic neuropathy. It is generally agreed that diabetic neuropathy should not be diagnosed on the basis of one symptom, sign or test alone. Dyck et al., recommended at least two abnormalities should be present in the diagnosis. ${ }^{4}$ In 1988, the San Antonio Conference on Diabetic Neuropathy by the American Diabetes Association and the American Academy of Neurology proposed that in order to diagnose diabetic neuropathy, the patient must have at least one abnormal measurement among the following tests: clinical symptoms, clinical examination, electrophysiological studies, quantitative sensory testing and autonomic function testing. ${ }^{5}$

Electrophysiological testing which includes nerve conduction velocities, are objective, sensitive and reproducible tests used in clinical neuropathy trials. ${ }^{6,7}$ Nerve conduction studies provide results with high

Corresponding author: Daryl Jade T. Dagang, MD

Section of Endocrinology, Diabetes and Metabolism

Department of Medicine, Philippine General Hospital

Taft Avenue, Ermita, Manila, Philippines 1000

Tel. No.: +632-554-84000 local 2230

Email address: daryldagang@gmail.com 
sensitivity of $92 \%$ for nerve dysfunction, ${ }^{8}$ however, the test is not readily available in most centers in the country; it is time-consuming, expensive and requires equipment and training. Several diagnostic screening tools have been developed and validated abroad to aid clinicians and researchers in identifying patients with neuropathy. Instruments such as the McGill Pain Questionnaire, the NeuroQol, and the Neuropathy Symptom Score (NSS) and its derivatives have been used in clinical trials, however, these tools make use of clinical symptoms only either self-reported by the patients or queried in a standardized manner by a trained individual.9-11 A neuropathic foot can be identified by simple clinical observation. Evidence might include small muscle wasting, clawing of toes, prominent metatarsal heads, dry skin, callus formation and body deformities. Two simple instruments have been developed for clinical practice and used in clinical trials that look into clinical signs of diabetic neuropathy - the Neuropathy Disability Score (NDS) and the Michigan Neuropathy Screening Instrument (MNSI) The NDS developed by Dyck and colleagues is a simple clinical examination that sums abnormalities of reflexes and sensory assessment. ${ }^{10}$ The test is reproducible and easily performed by trained and experienced physicians, however, it does not include subjective symptoms which may have adverse effects on the quality of life in diabetic neuropathy. ${ }^{12}$

In 1994, Feldman and colleagues designed the Michigan Neuropathy Screening Instrument, an outpatient program to facilitate diagnosis of distal symmetrical peripheral neuropathy among diabetics. It includes two separate assessments - a brief 15-item self-administered questionnaire and a lower extremity examination composing of visual inspection, vibratory sensation, and ankle reflexes. ${ }^{13}$ The instrument has the advantage of incorporating the patient's self-reported clinical symptoms and the physician's physical examination in one screening tool. The MNSI has a sensitivity of $80 \%$ and specificity of $95 \%$ and has been validated for patients with Type 1 diabetes included in the Diabetes Control and Complications Trial (DCCT) ${ }^{14}$ and Type 2 diabetes in Iran. ${ }^{15}$

Although clinical practice guidelines recommend annual screening for neuropathy, they are unable to support specific recommendations for screening maneuvers because of a lack of evidence for the validity of screening tests in the medical literature. ${ }^{16}$ Nerve conduction studies offer an objective and sensitive way to diagnose diabetic neuropathy however the availability of trained personnel and equipment is limited only to a few centers in the country. The MNSI or any other screening tool for diagnosis of diabetic neuropathy has not been validated in the Philippines. Some of the items in the questionnaire may not be culturally appropriate among Filipinos and modifications may be necessary. Thus, this study on the validity of MNSI in our local setting is of great importance for the prevention of diabetes-related foot problems especially in centers where means for early diagnosis of diabetic neuropathy is limited.

\section{OBJECTIVES}

1. To assess the validity of the Filipino-translated version of the Michigan Neuropathy Screening Instrument in screening for diabetic peripheral neuropathy among Filipino patients with Diabetes Mellitus using nerve conduction velocity studies as gold standard.

2. To determine the most accurate cut-off score for the diagnosis of neuropathy using MNSI among diabetic Filipino subjects.

\section{METHODOLOGY}

\section{Study Design}

Cross-sectional Analytic

\section{Study Setting}

This study was done at the Diabetes Clinic, General Medicine Clinic and Family Medicine Clinic, Out-Patient Department of the Philippine General Hospital, a tertiary hospital located in an urban setting.

\section{Study Subjects}

Patients with diabetes mellitus seen at the Diabetes, General Medicine and Family Medicine clinics were recruited through randomized sampling.

\section{Inclusion Criteria}

The study population is composed of patients aged $>18$ years, diagnosed with diabetes mellitus based on American Diabetes Association (ADA) 2014 criteria, able to read, write and understand the Filipino language, and consented to join in the study.

The study included patients with either type 1 or type 2 diabetes mellitus fulfilling the diagnosis based on the ADA 2014 criteria (fasting blood sugar $\geq 126 \mathrm{mg} / \mathrm{dL}$, two hour plasma glucose of $\geq 200 \mathrm{mg} / \mathrm{dL}$ after an oral glucose tolerance test, random blood sugar $\geq 200 \mathrm{mg} / \mathrm{dL}$ with symptoms of diabetes, or $\mathrm{HbA} 1 \mathrm{c}>6.5 \%) .{ }^{17}$

\section{Exclusion Criteria}

Patients recruited had their charts reviewed for the following exclusion criteria:

1. Had a history of stroke

2. With a co-morbid condition that predisposes them to somatic sensory dysfunction, namely:

a. Uremia (creatinine clearance of $<15 \mathrm{~mL} / \mathrm{min} / 1.73$ $\mathrm{m}^{2}$ with symptoms such as progressive weakness, fatigue, loss of appetite, nausea and vomiting, tremors, abnormal mental function, shallow respiration) 
b. Alcoholism (consumption of $>100 \mathrm{~g}$ of alcohol per day for at least two years $)^{18}$

c. Connective tissue diseases such as rheumatoid arthritis, systemic lupus erythomatosus, scleroderma and Sjögren's syndrome

d. Exposure to poisons such as heavy metals

e. Exposure to cancer medications

f. Infections such as leprosy, herpes zoster, and HIV

g. Neural Tumors such as neuromas, schwannomas, neurofibromas and malignant peripheral nerve sheath tumors

h. Thyroid diseases such as Graves's disease, Hashimoto's thyroiditis, and post-procedural hypothyroidism

i. Liver diseases such as cirrhosis, hepatitis and hepatocullar carcinoma

\section{Withdrawal Criteria}

Inclusion to the study was entirely voluntary. Withdrawal from the study was allowed should the patient decided to stop participating even if consent was already given.

\section{Sample size}

A total of 150 subjects will be recruited. Sample size computation was based on the formula specific for sensitivity and specificity studies where, sensitivity and specificity of MNSI from the original study, ${ }^{13} 80 \%$ and $95 \%$ respectively, and prevalence of neuropathy of $66 \%$ were used. ${ }^{1}$

\section{Sampling}

Stratified Sampling was done on this study and that each clinic (Diabetes, General Medicine, and Family Medicine) represented one category. Randomized sampling was done on pre-specified clinic days - every Mondays and Wednesdays, recruitment was done at the General Medicine Clinics, Tuesdays and Thursdays at Family Medicine Clinics and Fridays at the Diabetes Clinic. All diabetic patients on a given clinic day were summarized in a list which served as the sampling frame where random sampling using Table of Random Numbers was done. At least 5 patients were recruited on a given day.

\section{Development of MNSI Filipino Version}

The original MNSI tool (Appendix A) was translated into the Filipino language by translators from Sentro ng Wikang Filipino (Center for Filipino Language), University of the Philippines, Manila.

Two physicians and one diabetic patient did backtranslation from Filipino to English; all three were proficient in both the Filipino and English language and were blinded to the original English version. This was done to further examine the faithfulness and appropriateness to its original form. The back-translators were instructed to use simple language and provide a translation of what the item actually says, not interpret what he or she thinks the item is supposed to say, thereby capturing the literal meaning of the item.

\section{Initial Reliability Testing and Cultural Validation}

Twenty diabetic patients were recruited from the Diabetes Clinic and were asked to answer the Filipino MNSI tool after signing an informed consent. Responses were analyzed for reliability testing per item using Cronbach's alpha. Cultural validation was done by the same set of patients through cognitive debriefing interviews per item facilitated by the prinicipal investigator in a focused group discussion. ${ }^{19}$ The following questions were asked per item, per patient:

- Did you have difficulty answering the question?

- What does the question mean to you?

- Is the question relevant to your condition?

- How would you have worded the question?

The tool was scrutinized for content, grammar, and cultural differences from the original questionnaire and then was modified to create the final translated version.

\section{Training of the Principal Investigator}

The principal investigator underwent a short-course training and certification from the supervising investigators, an Endocrinology consultant and a Neurology consultant on proper physical examination for diabetic neuropathy as prescribed by the original MNSI tool (Appendix B) prior to commencement of data collection so to ensure that proper techniques will be carried out.

\section{Data Collection}

After the final tool was created, recruitment of subjects started by randomized sampling followed by obtaining a signed consent. Demographic data was collected using a standardized data sheet. Chart review was done in each subject where comorbidities and diabetic complications such as nephropathy and retinopathy were noted. When indicated in the diagnosis and upon review of medications, the patient was on antihypertensive medications, then the patient was classified to be hypertensive. Results of previous lipid profile were also reviewed for presence of dyslipidemia. The latest body mass index (BMI) of each patient was also determined to classify obesity based on the WHO Asia-Pacific criteria.

Each patient filled out the 15-item questionnaire. The history questionnaire was self-administered by the patient. If a watcher accompanied the patient, the watcher was allowed to only assist the patient in answering the questions; but it was the patient himself who filled out the questionnaire. The questionnaire was estimated to be completely aswerable within 15 minutes or less, but the time spent on answering the questions was also recorded. 
Responses were added to obtain the total score. Responses of "yes" to items 1-3, 5-6, 8-9, 11-12, 14-15 were each counted as one point. A "no" response to items 7 and 13 counted as one point. Item \#4 is a measure of impaired circulation and item \#10 is a measure of general aesthenia and were not included in the scoring. To decrease the potential for bias, all scoring information was eliminated from the patient version. A score of $\geq 7$ was considered abnormal. ${ }^{20}$

The principal investigator proceeded to do physical examination of the foot as indicated in the original MNSI (Appendix B).

Each patient was then sent to the EMG-NCV Station where a technician, blinded to the results, performed standard nerve conduction studies as reference standard. For the upper extremity, routine antidromic stimulations of the bilateral median, ulnar, and radial sensory nerves were done. In the lower extremity, bilateral stimulation of the sural and superficial peroneal sensory nerves and peroneal and tibial motor nerves were performed. In this test, the nerve was stimulated with several electrodes attached to the skin with tape or a special paste. Two electrodes were placed on the skin over the nerve. One electrode stimulates the nerve with a very mild electrical impulse and the other electrode records it. The resulting electrical activity was recorded by another electrode. This was repeated for each nerve being tested. The result was interpreted on the changes in latency, amplitude or nerve conduction from the given normal values. In peripheral neuropathy, there is slowing of all nerve conductions in more than one limb. Nerve conduction tests may take from 15 minutes to 1 hour or more. The co-investigators, a neurology resident and a neurology fellow, also blinded to the results of the screening tests, read and interpreted the nerve conduction velocity studies. One of the supervising investigators, a neurology consultant also blinded to the results, confirmed the readings.

\section{Data Analysis}

The performance of the MNSI questionnaire and examination in predicting confirmed clinical neuropathy was assessed by determining sensitivity, specificity, positive and negative predictive values. Sensitivity is the probability of having a positive questionnaire or examination in the presence of confirmed clinical neuropathy. Specificity is the probability of having normal (not positive) MNSI tests in the absence of confirmed clinical neuropathy. Positive predictive value is the proportion of subjects with neuropathy among those with positive MNSI questionnaires or examinations. Negative predictive value is the proportion of subjects without neuropathy among those with normal (not positive) MNSI tests.

All items in the questionnaire were coded as 0 for a negative response and 1 for a positive response (negative responses on items 7 and 13 counted as 1 point). For the examination, responses for the left and right feet were combined. For each measure of the examination (appearance, ulcer, reflex and vibration), a combined score $\geq 2.5$ was classified as abnormal. The sensitivity and specificity of each item in predicting confirmed clinical neuropathy was evaluated. Chi-square values was used to determine the maximum discriminatory capability of each question.

Analysis was also done on different cut-off scores to determine the most accurate cut-off for the study population. Receiver operating characteristic (ROC) curves was used to illustrate the relationship between the true positive ratio (sensitivity) and the false positive ratio (1specificity) of a test. Areas under the receiver operating characteristic curve (AUC) are a measure of the performance of a test in predicting the outcome of interest. An AUC value of 0.5 indicates that a test performs no better than chance. AUC values between 0.70 and 0.79 indicate fair test performance, values between 0.80 and 0.89 indicate good performance and values $\geq 0.9$ indicate excellent performance.

Data were analyzed using Microsoft Excel and SPSS.

\section{RESULTS}

The English version of the MNSI Questionnaire was translated into the Filipino Version. An initial reliability testing was done on 20 diabetic patients showing a Crohnbach's alpha value of 0.747 indicating high testing reliability. The MNSI Filipino Version was modified based on the output of the focus group discussion with the patients for cultural validation thereby creating the final version (Appendix C).

A total of 171 patients were randomly selected, of which 150 consented to join the study and undergo nerve conduction velocity studies, equivalent to the target sample size.

Among the 150 subjects, 111 (74\%) were females and 39 (26\%) were males. The mean age was $56.7 \pm 12.0$. The type of diabetes was not identified among the subjects as proper tests for diagnosis were not done for this study, but $42.7 \%$ were noted to be on insulin therapy. The mean duration of treatment for diabetes was 10.2 \pm 7.7 years at the time of inclusion.

The following comorbidities were noted to be present: hypertension 68.7\%; dyslipidemia $71.3 \%$; and obesity $44.7 \%$. The mean BMI was $25.1 \pm 4.7$. The presence of other microvascular complications of diabetes were also noted: diabetic nephropathy $21.3 \%$ and diabetic retinopathy $24.7 \%$. The mean FBS and HbA1c were $138.8 \pm 54.8 \mathrm{mg} / \mathrm{dL}$ and $7.8 \pm 1.8 \%$, respectively. Of the 150 subjects, $55(36.6 \%)$ had good sugar control with an $\mathrm{HbA} 1 \mathrm{c}$ of less than $7.0 \%$ as recommended by the ADA 2015 guidelines. 
MNSI Questionnaire scores and MNSI Examination scores were analyzed. Mean MNSI Questionnaire score was 4.5 \pm 2.6 whereas mean MNSI Examination score was $2.0 \pm 1.9$. Eighty seven (58\%) out of the 150 subjects were diagnosed to have diabetic neuropathy based on NCV. Each item of the MSNI Questionnaire was analyzed for sensitivity and specificity (Table 1). Sensitivity ranges from $3.4-85.1 \%$ and specificity ranges from $34.9 \%-98.4 \%$. The two most sensitive questions were item \#4 Do you get muscle cramps in your legs and/or feet? ("Nagkakapulikat $k a$ ba sa iyong mga binti at/o mga paa?") and item \#1 Are your legs and/or feet numb? ("Namamanhid ba ang iyong mga binti at/o mga paa?") with the sensitivity of $85.1 \%$ and $78.2 \%$ respectively. Whereas items \#15 Have you ever had an amputation? ("Naputulan ka na ba ng anumang bahagi ng iyong katawan?") and \#13 Are you able to sense your feet when you walk? ("Nararamdaman mo ba ang iyong mga paa kapag naglalakad?") were the most specific questions with specificity of $98.4 \%$ and $93.7 \%$ respectively. Four of the questionnaire items (\#1, \#2, \#4 and \#9) had significant discriminatory capability to diagnose diabetic neuropathy as an independent question.

Sensitivity and specificity of each physical examination were also analyzed (Table 2). Sensitivity ranges from $13.8 \%-74.7 \%$ and specificity ranges from $61.9-100 \%$. Loss of ankle reflex had the most significant discriminatory capability with a sensitivity of $74.7 \%$ and specificity of $68.8 \%, p=<0.001$.

Based on the original scoring algorithm, Item \#4 and Item $\# 10$ were excluded, as they are more of a measure of impaired circulation and general asthenia respectively. Using the algorithm, only $14(9.3 \%)$ had a score of $\geq 7$, with the sensitivity of $13.8 \%$ and specificity of $96.8 \%$. When the two questions were included in the scoring, sensitivity improved to $31.0 \%$. ROC curves were generated to determine the AUC, which will measure the performance of the test in predicting the outcome of interest (Figure 1). AUC for the original algorithm was 0.677 and AUC for the new algorithm that includes the two questions was 0.687 . Both indicated modest testing performance. Based on the coordinates of the curve, reducing the cut-off score to $\geq 4$ further improves the sensitivity and specificity of the test to $73.6 \%$ and $52.4 \%$ respectively. Comparison of the accuracy of cut-off scores and $\geq 7$ and $\geq 4$ is shown in (Table 3 ).

An ROC curve was also generated for the MNSI Examination, which showed an AUC of 0.787, significantly indicating fair test performance, $p=<0.001$. (Figure 2) With the cut-off of $\geq 2.5$ as indicated by the original MNSI algorithm, the sensitivity and specificity of the test are $52.9 \%$ and $84.1 \%$ respectively. Reducing the cut-off score to $\geq 1$ would improve the sensitivity and specificity of the test to $86.2 \%$ and $55.6 \%$ respectively.

Combining both MNSI Questionnaire and MNSI Examination, with cut-off scores of $\geq 4$ and $\geq 1$ respectively, significantly improves the test performance of the tool to a sensitivity of $95.4 \%$ with a specificity of $39.7 \%$, positive predictive value (PPV) of $81.3 \%$, negative predictive value (NPV) of 59.3\%, AUC=0.776, $p=<0.001$ (Figure 3).

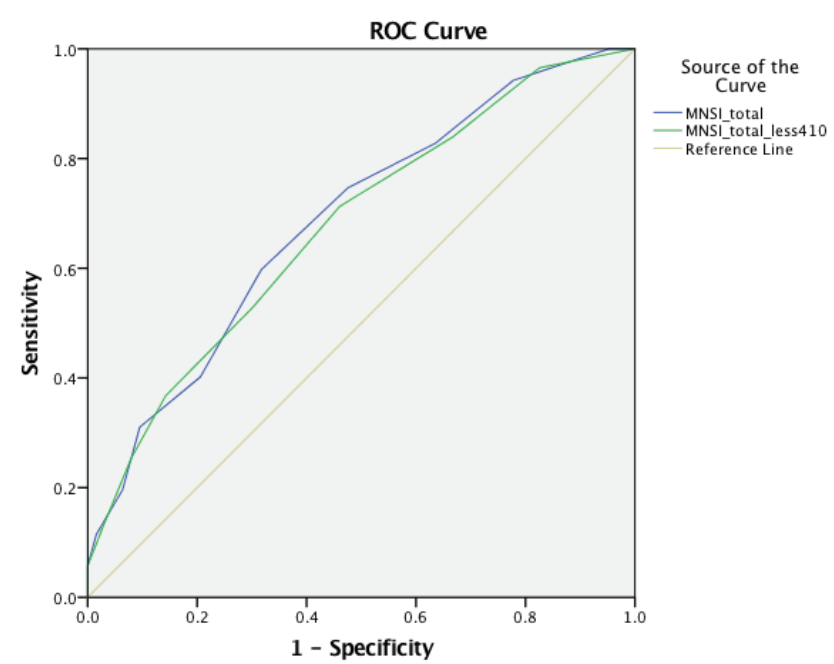

Figure 1. ROC Curves of the original MNSI algorithm vs the new MNSI algorithm (including item \#4 and \#10).

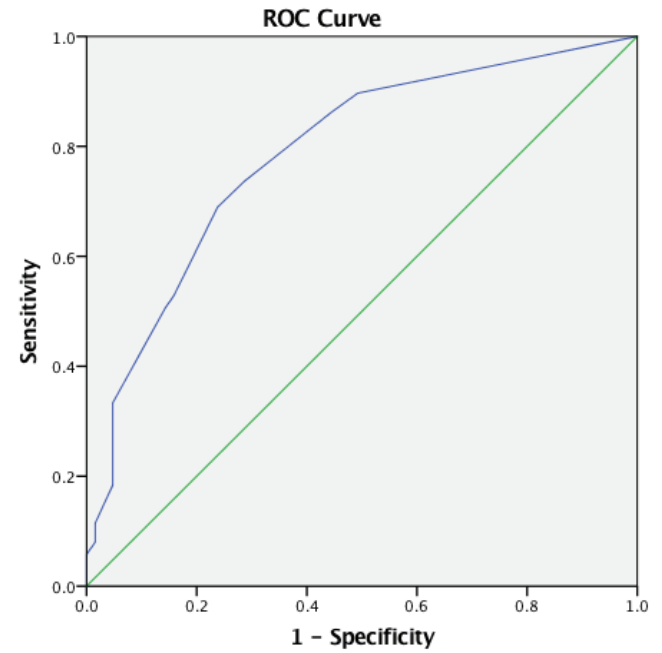

Figure 2. ROC Curve of the MNSI Examination.

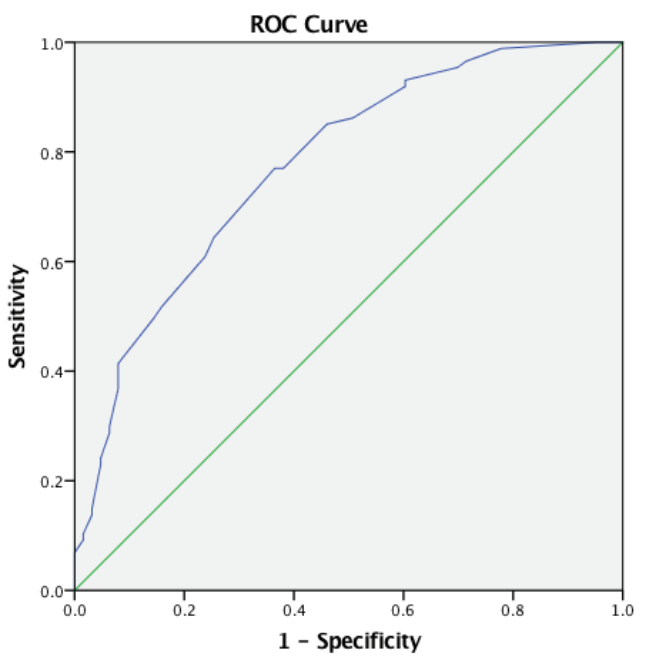

Figure 3. ROC Curve of Combined MNSI Questionnaire and MNSI Examination. 


\begin{tabular}{|c|c|c|c|c|c|c|c|}
\hline MNSI Questionnaire & & With Neuropathy & Without Neuropathy & Total & Sensitivity & Specificity & X2 Test \\
\hline Item 1 & $\begin{array}{l}\text { Yes } \\
\text { No }\end{array}$ & $\begin{array}{l}68 \\
19\end{array}$ & $\begin{array}{l}33 \\
33\end{array}$ & $\begin{array}{l}101 \\
49\end{array}$ & $78.2 \%$ & $47.6 \%$ & 0.001 \\
\hline Item 2 & $\begin{array}{l}\text { Yes } \\
\text { No }\end{array}$ & $\begin{array}{l}39 \\
48\end{array}$ & $\begin{array}{l}15 \\
48\end{array}$ & $\begin{array}{l}54 \\
96\end{array}$ & $44.8 \%$ & $76.2 \%$ & 0.008 \\
\hline Item 3 & $\begin{array}{l}\text { Yes } \\
\text { No }\end{array}$ & $\begin{array}{l}22 \\
65\end{array}$ & $\begin{array}{l}9 \\
54\end{array}$ & $\begin{array}{l}31 \\
119\end{array}$ & $25.3 \%$ & $85.7 \%$ & 0.101 \\
\hline Item 4 & $\begin{array}{l}\text { Yes } \\
\text { No }\end{array}$ & $\begin{array}{l}74 \\
13\end{array}$ & $\begin{array}{l}41 \\
22\end{array}$ & $\begin{array}{l}115 \\
35\end{array}$ & $85.1 \%$ & $34.9 \%$ & 0.004 \\
\hline Item 5 & $\begin{array}{l}\text { Yes } \\
\text { No }\end{array}$ & $\begin{array}{l}57 \\
30\end{array}$ & $\begin{array}{l}33 \\
30\end{array}$ & $\begin{array}{l}90 \\
60\end{array}$ & $65.5 \%$ & $47.6 \%$ & 0.105 \\
\hline Item 6 & $\begin{array}{l}\text { Yes } \\
\text { No }\end{array}$ & $\begin{array}{l}4 \\
59\end{array}$ & $\begin{array}{l}4 \\
83\end{array}$ & $\begin{array}{l}8 \\
142\end{array}$ & $4.6 \%$ & $93.7 \%$ & 0.638 \\
\hline Item 7 & $\begin{array}{l}\text { Yes } \\
\text { No }\end{array}$ & $\begin{array}{l}12 \\
75\end{array}$ & $\begin{array}{l}4 \\
59\end{array}$ & $\begin{array}{l}16 \\
134\end{array}$ & $13.8 \%$ & $93.7 \%$ & 0.145 \\
\hline Item 8 & $\begin{array}{l}\text { Yes } \\
\text { No }\end{array}$ & $\begin{array}{l}20 \\
67\end{array}$ & $\begin{array}{l}8 \\
55\end{array}$ & $\begin{array}{l}28 \\
122\end{array}$ & $23.0 \%$ & $87.3 \%$ & 0.110 \\
\hline Item 9 & $\begin{array}{l}\text { Yes } \\
\text { No }\end{array}$ & $\begin{array}{l}32 \\
55\end{array}$ & $\begin{array}{l}12 \\
51\end{array}$ & $\begin{array}{l}44 \\
106\end{array}$ & $36.8 \%$ & $81.0 \%$ & 0.019 \\
\hline Item 10 & $\begin{array}{l}\text { Yes } \\
\text { No }\end{array}$ & $\begin{array}{l}41 \\
46\end{array}$ & $\begin{array}{l}22 \\
41\end{array}$ & $\begin{array}{l}63 \\
87\end{array}$ & $47.1 \%$ & $65.1 \%$ & 0.135 \\
\hline Item 11 & $\begin{array}{l}\text { Yes } \\
\text { No }\end{array}$ & $\begin{array}{l}23 \\
64\end{array}$ & $\begin{array}{l}12 \\
51\end{array}$ & $\begin{array}{l}35 \\
115\end{array}$ & $26.4 \%$ & $81.0 \%$ & 0.291 \\
\hline Item 12 & $\begin{array}{l}\text { Yes } \\
\text { No }\end{array}$ & $\begin{array}{l}45 \\
42\end{array}$ & $\begin{array}{l}24 \\
39\end{array}$ & $\begin{array}{l}69 \\
81\end{array}$ & $51.7 \%$ & $61.9 \%$ & 0.098 \\
\hline Item 13 & $\begin{array}{l}\text { Yes } \\
\text { No }\end{array}$ & $\begin{array}{l}10 \\
77\end{array}$ & $\begin{array}{l}4 \\
59\end{array}$ & $\begin{array}{l}14 \\
136\end{array}$ & $11.5 \%$ & $93.7 \%$ & 0.285 \\
\hline Item 14 & $\begin{array}{l}\text { Yes } \\
\text { No }\end{array}$ & $\begin{array}{l}22 \\
65\end{array}$ & $\begin{array}{l}11 \\
52\end{array}$ & $\begin{array}{l}33 \\
117\end{array}$ & $25.3 \%$ & $82.5 \%$ & 0.253 \\
\hline Item 15 & $\begin{array}{l}\text { Yes } \\
\text { No }\end{array}$ & $\begin{array}{l}3 \\
84\end{array}$ & $\begin{array}{l}1 \\
62\end{array}$ & $\begin{array}{l}4 \\
146\end{array}$ & $3.4 \%$ & $98.4 \%$ & 0.485 \\
\hline
\end{tabular}

Table 2. Performance of the individual components of the MNSI Examination in predicting confirmed clinical neuropathy

\begin{tabular}{|c|c|c|c|c|c|c|c|}
\hline MNSI Examination & & With Neuropathy & Without Neuropathy & Total & Sensitivity & Specificity & X2 Test \\
\hline $\begin{array}{l}\text { Presence of abnormality } \\
\text { on inspection }\end{array}$ & $\begin{array}{l}\text { Yes } \\
\text { No }\end{array}$ & $\begin{array}{l}36 \\
51\end{array}$ & $\begin{array}{l}3 \\
60\end{array}$ & $\begin{array}{l}39 \\
111\end{array}$ & $41.4 \%$ & $95.2 \%$ & $<0.001$ \\
\hline Presence of ulcer & $\begin{array}{l}\text { Yes } \\
\text { No }\end{array}$ & $\begin{array}{l}12 \\
75\end{array}$ & $\begin{array}{l}0 \\
63\end{array}$ & $\begin{array}{l}12 \\
138\end{array}$ & $13.8 \%$ & $100 \%$ & 0.002 \\
\hline Loss of Ankle Reflex & $\begin{array}{l}\text { Yes } \\
\text { No }\end{array}$ & $\begin{array}{l}65 \\
22\end{array}$ & $\begin{array}{l}25 \\
38\end{array}$ & $\begin{array}{l}90 \\
60\end{array}$ & $74.7 \%$ & $68.8 \%$ & $<0.001$ \\
\hline Loss of Vibration Sense & $\begin{array}{l}\text { Yes } \\
\text { No }\end{array}$ & $\begin{array}{l}55 \\
32\end{array}$ & $\begin{array}{l}24 \\
39\end{array}$ & $\begin{array}{l}79 \\
71\end{array}$ & $63.2 \%$ & $61.9 \%$ & 0.002 \\
\hline
\end{tabular}

Table 3. Performance of MNSI Questionnaire at different cut-off values in predicting confirmed clinical neuropathy

\begin{tabular}{ccccc}
\hline MNSI Score & Sensitivity & Specificity & $\begin{array}{c}\text { Positive } \\
\text { PV }\end{array}$ & $\begin{array}{c}\text { Negative } \\
\text { PV }\end{array}$ \\
\hline$\geq 1$ & $100.0 \%$ & $4.8 \%$ & $59.2 \%$ & $100 \%$ \\
$\geq 4$ & $73.6 \%$ & $52.4 \%$ & $85.7 \%$ & $44.9 \%$ \\
$\geq 7$ & $31.0 \%$ & $90.5 \%$ & $81.8 \%$ & $48.7 \%$ \\
\hline
\end{tabular}

\section{DISCUSSION}

The early recognition of diabetic neuropathy is important for the following reasons: 1 . Non-diabetic neuropathies may be present in a diabetic patient, which may be treatable; 2 . Asymptomatic diabetic peripheral neuropathy may be present which puts the patient at risk for insensate injury to the foot; 3 . Treatment options already exist which includes glycemic control and both pharmacologic and non-pharmacologic strategies to alleviate the symptoms.

Many medications are available for the treatment of diabetic neuropathic pain. Oral agents include antidepressants and anticonvulsant drugs such as gabapentin and pregabalin, and topical medication such as capsaicin and transdermal lidocaine for localized pain and for those with intolerance to oral medications, are available for addressing neuropathic pain. Vitamin B supplementation is also often prescribed to reduce paresthesias. ${ }^{21}$

The ADA Guidelines recommends annual screening of diabetic neuropathy, however, no single screening tool was mentioned. Screening is usually through a combination of symptom report from the patient and clinical tests done by the physician, such as ankle reflexes, vibration sense, pin-prick and light touch perception. ${ }^{16}$ This approach is not standardized and lacks consistency and reproducibility. Electrophysiological testing, on the other hand, such as NCV is the gold standard, however, it is expensive, time-consuming, and available in certain centers only. Several tools have been developed and validated abroad which includes the MNSI; however, the tool has yet to be translated to the Filipino language and validated locally for clinical use here in the Philippines.

In this study, the MNSI tool was translated to the Filipino language and was validated using NCV as gold standard. When used separately, the MNSI questionnaire (AUC 0.687 ) and examination (AUC 0.787) performed similarly in predicting confirmed clinical neuropathy. We found, however, that the published cut-off point to define a positive test for the questionnaire $(\geq 7)$ was very insensitive, missing many patients with confirmed clinical neuropathy. 
Changing the cut point to define a positive test for the questionnaire to $\geq 4$ and $\geq 1$ for the examination harmonized the sensitivity and specificity of both tools. When used in combination, the sensitivity improved to $95.4 \%$, which is very suitable, as MNSI is just a screening tool to diagnose diabetic neuropathy. A highly sensitive test is more important for screening than it being more specific. For this study, the sensitivity of the tool is also more important that the PPV since PPV is not intrinsic to the test, and that the prevalence of DM neuropathy has to be considered for it to be useful. As of the moment, the prevalence of diabetic neuropathy among Filipino patients with diabetes has not been established yet. The prevalence of neuropathy in a tertiary hospital may be different from other institutions. However, it is notable that both the sensitivity and the PPV of the Filipino-version of MNSI are good (95.4\% and $81.3 \%$, respectively). Our findings are also similar to the validation of the MNSI tool among Type 1 diabetic patients enrolled in the DCCT, in which the questionnaire cut-off of $\geq 7$ was found to be insensitive and the test performance of the test was optimized at the cut-off of $\geq 4 .^{14}$

The performance of each item of the questionnaire in predicting the presence of diabetic neuropathy was analyzed. Item \#4 Do you get muscle cramps in your legs and/or feet? ("Nagkakapulikat ka ba sa iyong mga binti at/o mga paa?") and item \#1 Are your legs and/or feet numb? ("Namamanhid ba ang iyong mga binti at/o mga paa?") were found to be the most sensitive, although both questions were found to be not significantly able to discriminate diabetic neuropathy if used independently. These questions are more frequently being reported by diabetic patients in the clinics in comparison to the other items in the questionnaire. There is a higher chance that these symptoms are already present in someone who has yet to be diagnosed with diabetic neuropathy. Item \#6 Does it hurt when the bed covers touch your skin? ("Nasasaktan ka ba kapag nadadampian ng kumot ang iyong balat?"), item \#13 Are you able to sense your feet when you walk? ("Nararamdaman mo ba ang iyong mga paa kapag naglalakad?") and item \#15 Have you ever had an amputation ("Naputulan ka na ba ng anumang bahagi ng iyong katawan?") were all very specific probably because these events rarely happen in comparison to the other items in the questionnaire.

\section{CONCLUSION}

The analyses in 150 subjects confirm that the Filipinoversion of MNSI is a simple, non-invasive and valid measure of distal symmetrical peripheral neuropathy when compared with nerve conduction velocity as gold standard. The MNSI Questionnaire has to be used without excluding item $\# 4$ and item $\# 10$ with a cut-off score of $\geq 4$ instead of $\geq 7$, and the MNSI Examination cut-off should be $\geq 1$ instead of $\geq 2.5$. Combining the questionnaire and the examination increases the sensitivity of the tool. We recommend to use the combined Filipino-version of the
MNSI questionnaire and the MNSI examination to screen for diabetic neuropathy in clinical practice using the cut points for abnormal findings mentioned.

\section{Statement of Authorship}

All authors have given approval to the final version submitted.

\section{Author Disclosure}

All the authors have declared no conflict of interest to the work carried out in this paper.

\section{Funding Source}

This study was chosen as the recipient of the P150,000 Philippine Society of Endocrinology, Diabetes and Metabolism (PSEDM) Research Grant in Diabetes for the year 2015.

\section{References}

1. Dyck PJ, Kratz KM, Karnes JL, et al. The prevalence by staged severity of various types of diabetic neuropathy, retinopathy, and nephropathy in a population-based cohort. Neurology. 1993;43(4):817-24. https://doi.org/10.1212/WNL.43.4.817.

2. United Kingdom Prospective Diabetes Study (UKPDS) Group. Intensive blood-glucose control with sulphonylureas or insulin compared with conventional treatment and risk of complications in patients with type 2 diabetes. Lancet. 1998;352(9131):837-53. https://doi.org/10.1016/S0140-6736(98)07019-6.

3. Mulder DW, Lambert EH, Bastron JA, Sprague RG. The neuropathies associated with diabetes mellitus: A clinical and electromyographic study of 103 unselected diabetic patients. Neurology, 1961;11(4)Pt 1:275-84. PMID: 13773672.

4. Gires Arnold, et al. Severity and staging of diabetic polyneuropathy. Textbook of Diabetic Neuropathy. 2003;170-75. https://doi.org/10. 1055/b-0034-83069.

5. American Diabetes Association. Report and recommendations of the San Antonio Conference on Diabetic Neuropathy. Diabetes Care. 1988;11(7):592-7. https://doi.org/10.2337/diacare.11.7.592.

6. Diabetic polyneuropathy in controlled clinical trials: Consensus report of the peripheral nerve society. Ann Neurol. 1995;38(3):478-82. https://doi.org/10.1002/ana.410380323.

7. Dyck PJ, Norell JE, Tritschler $\mathrm{H}$, et al. Challenges in design of multicenter trials: End points assessed longitudinally for change and monotonicity. Diabetes Care. 2007;30(10):2619-25. https://doi.org/10. 2337/dc06-2479.

8. Perkins BA, Grewal J, Ng E,Ngo M, Bril V. Validation of a novel point-of-care nerve conduction device for the detection of diabetic sensorimotor polyneuropathy. Diabetes Care. 2006;29(9):2023-7. https://doi.org/10.2337/dc08-0500.

9. Boulton AJM, Malik RA, Arezzo JC, Sosenko JM. Diabetic somatic neuropathies. Diabetes Care. 2004;27(6):1458-87. https://doi.org/10. 2337/diacare.27.6.1458.

10. Dyck PJ, Melton III J, O'Brien PC, Service FJ. Approaches to improve epidemiological studies of diabetic neuropathy: Insights from the Rochester diabetic neuropathy study. Diabetes. 1997;46(Suppl 2):S5-8. https://doi.org/10.2337/diab.46.2.S5.

11. Vileikyte L, Peyrot M, Bundy C, et al. The development and validation of a neuropathy- and foot ulcer- specific quality of life instrument. Diabetes Care. 2003;26(9):2549- 55. https://doi.org/10. 2337/diacare.26.9.2549.

12. Vileikyte L, Rubin R, Leventhal H. Psychological aspects of diabetic neuropathic foot complications: An overview. Diabetes Metab Res Rev. 2004; 20(Suppl S1): S13-8. https://doi.org/10.1002/dmrr.437.

13. Feldman EL, Stevens MJ, Thomas PK, Brown MB, Canal N, Greene DA. A practical two-step quantitative clinical and electrophysiological assessment for the diagnosis and staging of diabetic neuropathy. Diabetes Care. 1996;17(11):1281-89. https://doi. org/10.2337/diacare.17.11.1281.

14. Herman WH, Pop-Busui R, Braffett BH, Martin CL, et.al. Use of the Michigan Neuropathy Screening Instrument as a measure of distal symmetrical peripheral neuropathy in type 1 diabetes: Results from the diabetes control and complications trial/epidemiology of diabetes interventions and complications. Diabet Med. 2012;29(7):937-44. https://doi.org/10.1111/j.1464-5491.2012.03644.x. 
15. Mohgtaderi A, Bakhshipour A, Rashidi H. Validation of Michigan neuropathy screening instrument for diabetic peripheral neuropathy. Clin Neurol Neurosurg. 2006;108(5):477-81. https://doi.org/10.1016/ j.clineuro.2005.08.003.

16. Mayfield JA, Reiber GE, Sanders LJ, Janisse D, Pogach LM; American Diabetes Association. Preventive foot care in people with diabetes. Diabetes Care. 2003;26(Suppl 1):s78-9. PMID: 12502623.

17. American Diabetes Association. Standards of Medical Care in Diabetes-2014. Diabetes Care. 2014;37(Suppl 1):S14-80. https://doi. org/10.2337/dc14-S014.

18. Ammendola A, Tata M, Aurilio C, et al. Peripheral neuropathy in chronic alcoholism: A retrospective cross-sectional study in 76 subjects. Alcohol Alcohol. 2001;36(3): 271-5. PMID: 11373267.
19. Eremenco SL, Cella D, Arnold BJ. A comprehensive method for the translation and cross-cultural validation of health status questionnaires. Eval Health Prof. 2005;28(2):212-32. https://doi.org/ $10.1177 / 0163278705275342$.

20. University of Michigan Health System [Internet]. Michigan: Regents of the University of Michigan. How to Use the Michigan Neuropathy Screening Instrument. Available from: https://www.med.umich.edu/ mdrtc/profs/documents/svi/MNSI_howto.pdf.

21. Ziegler D. Treatment of diabetic neuropathy and neuropathic pain: How far have we come? Diabetes Care. 2008;31(Suppl 2):S255-61. http://dx.doi.org/10.2337/dc08-s263. (Retraction published 2012, Diabetes Care. 2012;35(2):456).

\section{APPENDIX}

\section{Appendix A. Michigan Neuropathy Screening Instrument}

A. History (To be completed by the person with diabetes)

Please take a few minutes to answer the following questions about the feeling in your legs and feet. Check Yes or No based on how you usually feel. Thank you.

1. Are your legs and/or feet numb?

2. Do you ever have any burning pain in your legs and/or feet?

3. Are your feet too sensitive to touch?

4. Do you get muscle cramps in your legs and/or feet?

5. Do you ever have any prickling feelings in your legs or feet?

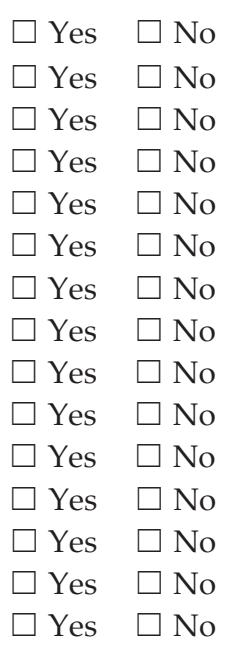

6. Does it hurt when the bed covers touch your skin?

7. When you get into the tub or shower, are you able to tell the hot water from the cold water?

8. Have you ever had an open sore on your foot?

9. Has your doctor ever told you that you have diabetic neuropathy?

10. Do you feel weak all over most of the time?

11. Are your symptoms worse at night?

12. Do your legs hurt when you walk?

13. Are you able to sense your feet when you walk?

14. Is the skin on your feet so dry that it cracks open?

15. Have you ever had an amputation?

Total

B. Physical Assessment (To be completed by health professional)

1. Appearance of Feet

\begin{tabular}{|c|c|c|c|c|c|c|}
\hline & & Right & & & Left & \\
\hline & a. $\mathrm{N}$ & rmal $\square 0$ Yes & $\neg 1$ No & & ormal $\square 0$ Yes & $\square 1$ No \\
\hline & b. If & o, check all that & apply: & & no, check all tha & apply: \\
\hline & & Deformities & & & Deformities & \\
\hline & & Dry skin, callus & & & Dry skin, callu & \\
\hline & & Infection & & & Infection & \\
\hline & & Fissure & & & Fissure & \\
\hline & & $\begin{array}{l}\text { Other } \\
\text { specify: }\end{array}$ & 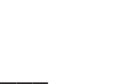 & & $\begin{array}{l}\text { Other } \\
\text { specify: }\end{array}$ & \\
\hline & & Right & & & Left & \\
\hline & $\mathrm{Abs}$ & & esent & & ent & sent \\
\hline 2. Ulceration & $\square$ & & $\square 1$ & & & $\square 1$ \\
\hline 3. Ankle Reflexes & $\begin{array}{c}\text { Present } \\
\square 0\end{array}$ & $\begin{array}{c}\text { Right } \\
\text { Reinforcement } \\
\square 0.5\end{array}$ & $\begin{array}{c}\text { Absent } \\
\square 1\end{array}$ & $\begin{array}{c}\text { Present } \\
\square 0\end{array}$ & $\begin{array}{c}\text { Left } \\
\text { Reinforcement } \\
\square 0.5\end{array}$ & $\begin{array}{c}\text { Absent } \\
\quad \square 1\end{array}$ \\
\hline & & Right & & & Left & \\
\hline & Present & Decreased & Absent & Present & Decreased & Absent \\
\hline 4. Vibration Perception & $\square 0$ & $\square 0.5$ & $\square 1$ & $\square 0$ & $\square 0.5$ & $\square 1$ \\
\hline
\end{tabular}

Signature:

Total Score: 


\section{Appendix B. How to Use the Michigan Screening Instrument}

\section{History}

The history questionnaire is self-administered by the patient. Responses are added to obtain the total score. Responses of "yes" to items 1-3, 5-6, 8-9, 11-12, 14-15 are each counted as one point. A "no" response on items 7 and 13 counts as 1 point. Item \#4 is a measure of impaired circulation and item \#10 is a measure of general aesthenia and are not included in scoring. To decrease the potential for bias, all scoring information has been eliminated from the patient version.

\section{Physical Examination}

Foot Inspection. The feet were inspected for evidence of the presence of deformities, dry skin, calluses, infections, and fissures. Deformities include flat feet, hammer toes, overlapping toes, halux valgus, joint subluxation, prominent metatarsal heads, medial convexity (Charcot foot) and amputation. Each foot with any abnormality received a score of 1 . Each foot was also inspected for ulcers and each foot with an ulcer received a score of 1 .

Muscle Stretch Reflexes. The ankle reflexes were examined using an appropriate reflex hammer. The ankle reflexes were elicited in the sitting position with the foot dependent and the patient relaxed. For the reflex, the foot was passively positioned and the foot dorsiflexed slightly to obtain optimal stretch of the muscle. The Achilles tendon was percussed directly. If the reflex is obtained, it was graded as present. If the reflex is absent, the patient was asked to perform the Jendrassic maneuver (i.e., clenching the teeth and hooking the fingers together and pulling). Reflexes elicited with the Jendrassic maneuver alone were designated "present with reinforcement" and was scored as 0.5. If the reflex is absent, even in the face of the Jendrassic maneuver, the reflex was considered absent and was scored as 1.

Vibration Sense. Vibration sensation was performed with the great toe unsupported. Vibration sensation was tested bilaterally using a $128 \mathrm{~Hz}$ tuning fork placed over the dorsum of the great toe on the boney prominence of the DIP joint. The patient, whose eyes were closed, was asked to indicate when he can no longer sense the vibration from the vibrating tuning fork. In general, the investigator should be able to feel vibration in his hand for 5 seconds longer than a normal subject can at the great toe. If the examiner felt the vibration for 10 or more seconds on his or her finger, then vibration was considered decreased. A trial was given when the tuning fork is not vibrating to be certain that the patient is responding to vibration and not pressure or some other clue. Vibration was scored as present if the examiner senses the vibration on his or her finger for $<10$ seconds (scored as 0 ), reduced if sensed for $\geq 10$ (scored as 0.5 ) or absent (no vibration detection) (scored as 1). The total possible score was 8 points and, in the published scoring algorithm, a score $\geq 2.5$ was considered abnormal.

\section{Appendix C. Michigan Neuropathy Screening Instrument (Filipino Version)}

\section{A. Kasaysayan (Sasagutan ng taong may diabetes)}

Maglaan ng ilang minuto sa pagsagot ng mga sumusunod na tanong ukol sa mga nararamdaman sa binti at paa. Piliin ang Oo o Hindi batay sa madalas mong nararamdaman. Salamat.

1. Namamanhid ba ang iyong mga binti at/o mga paa?

2. Nakararamdam ka ba ng nakapapasong kirot si iyong mga binti at/o paa?

3. Masyado bang sensitibo ang iyong mga paa kapag nahihipo?

4. Nagkakapulikat ka ba sa iyong mga binti at/o paa?

5. Nakararamdam ka ba na parang may tumutusok-tusok sa iyong mga binti at/o paa?

6. Nasasaktan ka ba kapag nadadampian ng kumot ang iyong balat?

7. Habang naliligo, nararamdaman mo ba kung mainit o malamig ang tubig na ginagamit?

8. Nagkaroon ka ba ng bukas na sugat na matagal gumaling sa iyong paa?

9. Nasabihan ka ba ng iyong doktor na mayroon kang diabetic neuropathy?

10. Madalas ka ba makaramdam ng panghihina ng buong katawan?

11. Mas malala ba ang mga sintomas mo sa gabi?

12. Sumasakit ba ang iyong mga binti kapag naglalakad?

13. Nararamdaman mo ba ang iyong mga paa kapag naglalakad?

14. Masyado bang tuyo ang balat sa iyong paa na nagkakaroon ito ng mga bitak-bitak?

$\begin{array}{ll}\square \text { Oo } & \square \text { Hindi } \\ \square \text { Oo } & \square \text { Hindi } \\ \square \text { Oo } & \square \text { Hindi } \\ \square \text { Oo } & \square \text { Hindi } \\ \square \text { Oo } & \square \text { Hindi } \\ \square \text { Oo } & \square \text { Hindi } \\ \square \text { Oo } & \square \text { Hindi } \\ \square \text { Oo } & \square \text { Hindi } \\ \square \text { Oo } & \square \text { Hindi } \\ \square \text { Oo } & \square \text { Hindi } \\ \square \text { Oo } & \square \text { Hindi } \\ \square \text { Oo } & \square \text { Hindi } \\ \square \text { Oo } & \square \text { Hindi } \\ \square \text { Oo } & \square \text { Hindi } \\ \square \text { Oo } & \square \text { Hindi }\end{array}$

15. Naputulan ka na ba ng anumang bahagi ng iyong katawan?

Total 
Authors are required to accomplish, sign and submit scanned copies of the JAFES Author Form consisting of: (1) the Authorship Certification that the manuscript has been read and approved by all authors, and that the requirements for authorship have been met by each author, (2) the Author Declaration that the article represents original material that is not being considered for publication or has not been published or accepted for publication elsewhere, (3) the Statement of Copyright Transfer[accepted manuscripts become the permanent property of the JAFES and are licensed with an Attribution-Share Alike-Non-Commercial Creative Commons License. Articles may be shared and adapted for non-commercial purposes as long as they are properly cited], (4) the Statement of Disclosure that there are no financial or other relationships that might lead to a conflict of interest. For Original Articles involving human participants, authors are required to submit a scanned copy of the Ethics Review Approval of their research. For manuscripts reporting data from studies involving animals, authors are required to submit a scanned copy of the Institutional Animal Care and Use Committee approval. For Case Reports or Series, and Images in Endocrinology, consent forms are required for the publication of information about patients. Articles and any other material published in the JAFES represent the work of the author(s) and should not be construed to reflect the opinions of the Editors or the Publisher.

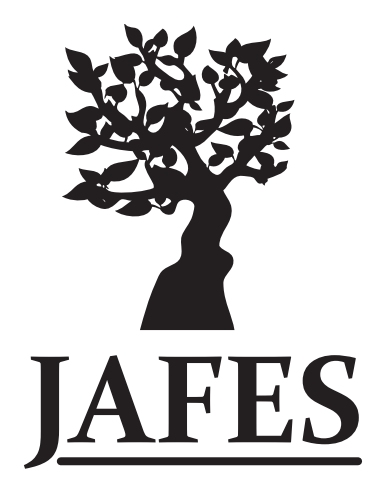

\section{Unique, interesting, enlightening. Your case report and the JAFES.}

